\title{
Energy and economic analysis of an ORC combined to steam boiler
}

\author{
Gabriel Mocanu ${ }^{1}$, Ion V. Ion ${ }^{1, *}$, and Cristian Iosifescu $^{1}$ \\ 1"'Dunărea de Jos" University of Galati, 47 Domneasca St., 800008 Galati, Romania
}

\begin{abstract}
Energy and economic performance of an organic Rankine cycle (ORC) system designed to recycle waste heat of a steam boiler was analysed. Optimisation of ORC system was performed by using the CycleTempo software and the REFPROP program. The selected working fluid was R245fa. For the exhaust gases temperature of $163^{\circ} \mathrm{C}$ and mass flow rate of $11.83 \mathrm{~kg} / \mathrm{s}$, cooling water temperature of $20^{\circ} \mathrm{C}$ resulted a gross efficiency of $21.02 \%$ and a cost of $2987 € / \mathrm{kW}$, an electricity levelised cost of $102 \mathrm{€} / \mathrm{kWh}$ and a payback period of 5.5 years.
\end{abstract}

\section{Introduction}

Reducing fossil fuel consumption and environmental pollution can be achieved by using renewable energy sources and by recovering waste heat from energy conversion processes. Waste heat can be recovered by using various technologies, such as: ORC, Kalina cycle, Goswami cycle, absorption refrigeration and heat pumps.

Since it was invented, in the 19th century, the steam boiler has known a continuous development, being found in all industries (food processing, chemicals, petroleum refining, pulp and paper, etc.). In the USA, steam boilers are responsible for burning about $37 \%$ of the fossil fuel consumed in industry [1]. Given the widespread use and appreciable consumption of fuels, the attention of specialists has been drawn to the increasing energy efficiency of steam boilers [2 - 6]. The thermal efficiency of steam boiler is greatly affected by the heat loss with the exhausted gases (probably the greatest heat loss). The exhaust gases from steam boilers have quite high temperatures, between $170^{\circ} \mathrm{C}$ and $120^{\circ} \mathrm{C}$, depending on the fuel burnt, in order to minimize the risk of corrosion and to ensure the dispersion of the flue gas at a height as high as possible. For heat recovery from exhaust gases from boilers are used ORC [7] and Kalina cycle [8, 9] to generate electrical energy, absorption refrigeration [10] for cooling and heat pumps to generate heat energy [11-13].

In [7] is reported a thermal efficiency of $14.82 \%$ of an ORC system with R123 as working fluid that recovers heat from the exhaust gases from a boiler by cooling them from $135^{\circ} \mathrm{C}$ to $110^{\circ} \mathrm{C}(29.26 \mathrm{MW})$, the condensation temperature being $30^{\circ} \mathrm{C}$.

Paper [8] presents the study on an ORC system used to recover the heat from exhaust gases from a steam boiler with a maximum gross efficiency of $18.8 \%$, by cooling them from $180^{\circ} \mathrm{C}$ to $130^{\circ} \mathrm{C}(2.3 \mathrm{MW})$ and by using cooling water with temperature of $5^{\circ} \mathrm{C}$.

\footnotetext{
* Corresponding author: iion@ugal.ro
} 
Heat recovery from exhaust gases from a boiler to generate electricity can be performed also by using Kalina cycle which can reach an efficiency of $14.78 \%$ by cooling them from $160^{\circ} \mathrm{C}$ to $105^{\circ} \mathrm{C}[10]$.

To generate electricity from low-temperature energy sources available at temperatures of $(80-150)^{\circ} \mathrm{C}$, the ORC systems are recommended [14]. Although ORC systems are a mature technology, their use is limited, mainly due to the fact that potential investors and users do not recognise the ability of these systems to conserve energy [15]. The efficiency, size and cost of an ORC system depend primarily on the working fluid, which is chosen according to the temperature of the heat source, and then on the evaporation temperature, condensation temperature and system configuration. There are many studies on working fluid selection for a particular application [14, 16-18]. In addition to the type of application and the temperature of the heat source, the selection of working fluid also takes into account the following: the auto-ignition temperature, which must be much higher than the maximum working temperature of the fluid; the enthalpy drop in the expander must be as large as possible to minimize fluid flow to the pump; in the T-s diagram, the inclination of the saturation curve must be as close as possible to the isentropic curves in order to avoid overheating; ODP and GWP to be minimal; fluid cost to be reduced; the critical temperature should be reduced because the vapour density is higher at lower temperatures. There is no fluid that meets all the criteria (environmental: ODP, GWP, flammability, toxicity; safety; physical and chemical properties; economic). The selection is finally made taking into account the international protocols that recommend fluids that are not harmful to the environment and the thermal efficiency of the cycle. In [19], working fluids are classified into six categories according to the heat source temperature. For heat source temperatures between $445 \mathrm{~K}$ and $465 \mathrm{~K}$, the following working fluids are recommended: R600, R245fa, neopentane and $\mathrm{R} 245 \mathrm{ca}$. Also, in paper [20], for temperature ranges $100-150^{\circ} \mathrm{C}$, are recommended the following fluids: butane, neopentane and R245fa.

For ORC systems with a capacity of more than $100 \mathrm{~kW}$, the most suitable expansion machines are turbines [21].

When using low heat sources, it is recommended the direct heat exchange between the heat source fluid and the ORC working fluid, without using an intermediate loop, thus avoiding the reduction of the evaporation temperature and the complication of the plant.

The specific cost of ORC units is difficult to be estimated due the lack of information provided by the manufactures, but in literature can be found some indicative costs and models to calculate them. The low temperature ORC systems can have an average specific cost from about $1350 € / \mathrm{kW}$ for a $250 \mathrm{~kW}$-unit to $2200 € / \mathrm{kW}$ for 50 $\mathrm{kW}$-unit, and the high temperature ORC systems from $1000 € / \mathrm{kW}$ for a $2 \mathrm{MW}$-unit, to $2000 € / \mathrm{kW}$ for a $500 \mathrm{~kW}$-unit and up to $3000 € / \mathrm{kW}$ for a $150 \mathrm{~kW}$-unit [22]. To the total acquisition cost $\left(Z_{t o t}\right)$ are added the following costs: $30 \%$ from the $Z_{t o t}$ for piping and accessories, $20 \%$ for installation; $10 \%$ for instrumentation and $11 \%$ for materials necessary to build the system. Operating and maintenance costs can reach $45 \%$ from the $Z_{\text {tot }}$ [18].

This paper aims to analyse energetically and economically the coupling of ORC to a steam boiler for heat recovery from exhaust gases.

\section{Energy model}

The steam boiler considered in this study is of type CR $12 \mathrm{C}$ and generates $50 \mathrm{t} / \mathrm{h}$ steam with a pressure of 36 bar and a temperature of $450^{\circ} \mathrm{C}$ with an efficiency of $90.5 \%$. The boiler runs on natural gas. The properties of the exhaust gases from the boiler are given in Tab. 1. 
Table 1. Flue gas properties.

\begin{tabular}{|c|c|c|}
\hline Temperature, ${ }^{\circ} \mathrm{C}$ & Mass flow rate, $\mathrm{kg} / \mathrm{s}$ & Enthalpy, $\mathrm{kJ} / \mathrm{kg}$ \\
\hline 163 & 11.83 & 242.25 \\
\hline 100 & 11.83 & 148.00 \\
\hline
\end{tabular}

The ORC model was developed by using the Cycle-Tempo simulation tool. The working fluid properties were calculated by using the REFPROP program. Of the recommended working fluids for the heat source temperature of $163^{\circ} \mathrm{C}$, the $\mathrm{R} 245 \mathrm{fa}$ was chosen as it need not superheating, has low ODP, is nearly non-toxic and it does not degrade at the maximum working temperature of the cycle. The chosen expansion machine was axial turbine.

Several ORC simulations were performed with different vaporization and condensation pressures with simple cycle and with internal heat recovery cycle aiming at obtaining the maximum net power. These led to the ORC configuration shown in Fig. 1 and the representation in the $T-s$ diagram in Fig. 2. The maximum net power was obtained for the evaporation pressure of 17 bar, condensation pressure of 2.6 bar and simple configuration. The pinch point temperature in evaporator and condenser was set at $10^{\circ} \mathrm{C}$. The evaporator is a shell-and-tube heat exchanger and the condenser is a flat plate heat exchanger.

The ORC operation parameters of the system components are given in Table 2 . The heat loss and pressure drop in pipes were neglected.

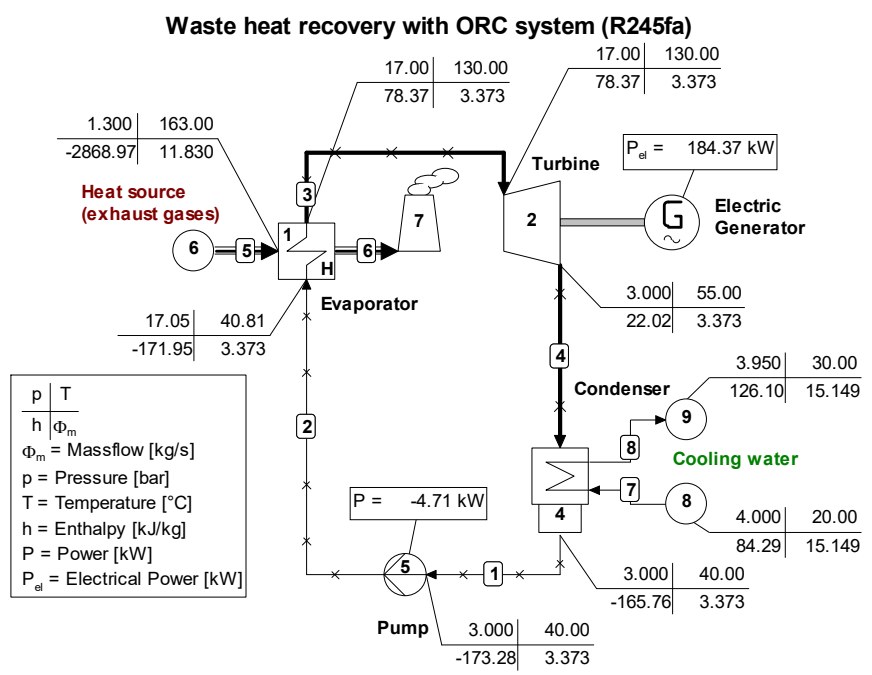

Fig. 1. ORC schematic (R245fa) (Cycle-Tempo).

The thermodynamic model is described by the following equations:

- pump power consumption:

$$
W_{P}=\dot{m}_{1}\left(h_{2}-h_{1}\right) / \eta_{i, p} \eta_{m, p}, \mathrm{~kW}
$$




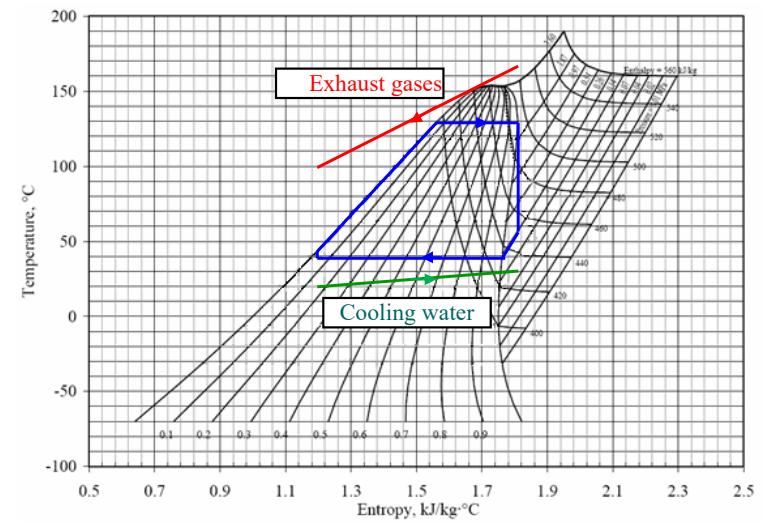

Fig. 2. $T$-s diagram of ORC (R245fa).

Table 2. Characteristics of system apparatuses.

\begin{tabular}{|l|c|}
\hline \multicolumn{1}{|c|}{ Parameter } & Value \\
\hline Turbine isentropic efficiency, $\eta_{i, T}$ & 0.87 \\
\hline Turbine mechanical efficiency, $\eta_{m, T}$ & 0.95 \\
\hline Pump isentropic efficiency, $\eta_{i, P}$ & 0.80 \\
\hline Pump mechanical efficiency, $\eta_{m, P}$ & 0.95 \\
\hline Electrical generator efficiency, $\eta_{\mathrm{G}}$ & 0.97 \\
\hline Pressure loss in evaporator and condenser & $0.05 \mathrm{bar}$ \\
\hline Evaporator overall heat transfer coefficient, $U_{e v}$ & $0.3 \mathrm{~kW} / \mathrm{m}^{2} / \mathrm{K}$ \\
\hline Condenser overall heat transfer coefficient, $U_{c}$ & $4 \mathrm{~kW} / \mathrm{m}^{2} / \mathrm{K}$ \\
\hline
\end{tabular}

- heat transferred in evaporator:

$$
\begin{gathered}
\dot{Q}_{e v}=\dot{m}_{f g}\left(h_{5}-h_{6}\right)=\dot{m}_{2}\left(h_{3}-h_{2}\right), \mathrm{kW} \\
\dot{Q}_{e v}=U_{e v} \cdot A_{e v} \cdot \Delta t_{e v}, \mathrm{~kW}
\end{gathered}
$$

where: $A_{e v}$ is evaporator heat exchange area, $\mathrm{m}^{2} ; U_{e v}$ is overall heat transfer coefficient, $\mathrm{kW} / \mathrm{m}^{2} / \mathrm{K} ; \Delta t_{e v}$ is logarithmic mean temperature difference of evaporator, $\mathrm{K}$;

- electric generator power output:

$$
W_{G}=\dot{m}_{1}\left(h_{3}-h_{4}\right) \eta_{m, T} \eta_{i, T} \eta_{G}, \mathrm{~kW}
$$

- heat transferred in condenser:

$$
\begin{gathered}
\dot{Q}_{c}=\dot{m}_{1}\left(h_{4}-h_{1}\right)=\dot{m}_{c w}\left(h_{8}-h_{7}\right), \mathrm{kW} \\
\dot{Q}_{c}=U_{c} \cdot A_{c} \cdot \Delta t_{c}, \mathrm{~kW}
\end{gathered}
$$


where: $A_{c}$ is evaporator heat exchange area, $\mathrm{m}^{2} ; U_{c}$ is overall heat transfer coefficient, $\mathrm{kW} / \mathrm{m}^{2} / \mathrm{K} ; \Delta t_{c}$ is logarithmic mean temperature difference of evaporator, $\mathrm{K} ; m_{c w}$ is mass flow rate of cooling water, $\mathrm{kg} / \mathrm{s}$;

- ORC net power output:

$$
W_{n e t}=W_{G}-W_{P}, \mathrm{~kW}
$$

- ORC gross energy efficiency:

$$
\eta=\frac{W_{n e t}}{\dot{Q}_{e v}}
$$

\section{Economic model}

The economic model includes calculation of capital cost, levelised cost of energy and the payback period.

The purchase cost corresponding to year 2001 of the ORC system components can be calculated by using the following equations [23]:

- turbine cost as function of power output, $W_{T}$ :

$$
Z_{T}=3.5 \cdot 10^{\left(2.2476+1.49658 \cdot \log _{10} W_{T}-0.1618 \cdot\left(\log _{10} W_{T}\right)^{2}\right.}, €
$$

- cost of heat exchangers as function of heat exchange area, $A$ :

$$
Z_{H E}=10000+324 \cdot A^{0.91}, €
$$

- pump cost as function of power capacity, $W_{P}$ and operation pressure $p$ :

$$
Z_{P}=10^{\left(3.3892+0.0536 \cdot \log _{10} W_{P}-0.1538 \cdot\left(\log _{10} W_{P}\right)^{2}\right.} \cdot 10^{\left(-0.3935+0.3957 \cdot \log _{10} p-0.0023 \cdot\left(\log _{10} p\right)^{2}\right.}, €
$$

- electrical generator cost as function of power output, $W_{G}$ :

$$
Z_{G}=2775000\left(\frac{W_{G}}{11800}\right)^{0.94}, €
$$

- total capital cost corresponding to year 2021:

$$
Z_{\text {tot }}=\left(Z_{T}+Z_{C}+Z_{P}+Z_{E V}\right) \frac{C E P C I_{2021}}{C E P C I_{2001}}, €
$$

where $C E P C I_{2001}$ and $C E P C I_{2021}$ are the Chemical Engineering Plant Cost Index values required to convert the purchase cost from 2001 to $2021\left(C E P C I_{2001}=397 ; C E P C I_{2021}=\right.$ 637.8) [24];

- capital recovery cost:

$$
C R F=\frac{i(1+i)^{n}}{(1+i)^{n}-1}
$$

where $i$ is annual interest rate $(i=0.1)$ and $n$ is plant lifetime ( $n=25$ years); 
- levelised cost of electricity:

$$
L C O E=\frac{Z_{\text {tot }} \cdot C R F+C_{O M}}{N \cdot W_{\text {net }}}, € / \mathrm{kWh}
$$

where $C_{O M}$ is the annual cost of plant operation and maintenance, $€\left(C_{O M}=0.3 \cdot Z_{t o t}\right), N$ is annual hours of operation ( $N=7400$ hours);

- payback period:

$$
P P=\frac{Z_{t o t}}{N \cdot W_{n e t} \cdot C_{e l}-C_{O M}}, \text { years }
$$

\section{Results and discussions}

The developed model was verified and validated by simulating the experimental ORC system working with R245fa presented in [25] and comparing the simulation results. The results of the simulation were very close to those presented in the paper.

Following the simulations performed with Cycle-Tempo, the optimal operating parameters of the system corresponding to the maximum net power generated by the ORC were obtained. These are given in Fig. 1. The ORC system recovers $844.29 \mathrm{~kW}_{\text {th }}$ from the exhaust flue gases from the boiler and generates $177.48 \mathrm{~kW}_{\mathrm{el}}$, which means a gross efficiency of $21.02 \%$.

In paper [10] is presented a system with Kalina cycle that recovers $2538 \mathrm{~kW}_{\text {th }}$ from the exhaust gases from a steam boiler. The power generated by the system is $375.21 \mathrm{~kW}_{\mathrm{el}}$ which means an efficiency of $14.78 \%$. If the same amount of heat with the same thermal level were recovered with the developed ORC system, $520.7 \mathrm{~kW}_{\mathrm{el}}$ would be generated, which means a system efficiency of $20.5 \%$. It can be seen that the ORC is more efficient than the Kalina cycle for using the same heat source and the same cooling water. On the other hand the Kalina cycle has an important advantage of reacting to the heat source temperature variation by adjusting the amount of ammonia in the working fluid.

For the implementation of the ORC system, a financial effort at the level of year 2021 of $531770 €$ is required, which means a specific cost of $2987 € / \mathrm{kW}_{\mathrm{el}}$. For the annual operation and maintenance cost of $€ 93300$, lifetime of 25 years and 7400 operating hours per year resulted in a Levelised cost of electricity of $0.115 € / \mathrm{kWh}$ and a payback of 5.5 years.

Comparing the results of energy analysis as well as of the economic analysis obtained in this study with those reported in the literature, insignificant differences can be observed.

\section{Conclusions}

One way to increase the steam boiler efficiency is to recover the heat from exhaust gasses. So, the exhaust gases should be cooled down as much as it is allowed and to reintroduce it to the cycle or to convert it into electricity as efficient as possible. The ORC systems are gaining attention for waste heat recovery. There are currently a wide variety of ORC systems that differ in working fluid, expansion machine type and heat exchangers type. The correct choice of system for a particular application depends primarily on the temperature of the heat source. Cycle-Tempo is one of the tools used to simulate ORC systems. It has the advantage of allowing operation optimisation of simulated systems.

The analysis performed in this paper shows that by cooling the exhaust gases from a steam boiler into the evaporator of an ORC system allows to generate electricity with an 
efficiency of $21.02 \%$. Heat recovery for electricity generation allows an annual reduction of GHG emissions of 360 tons and an annual gain of $190436 €$, obtained by selling electricity (by $0.145 € / \mathrm{kWh}$ ) or by reducing the electricity consumption. The generated electricity can be used to supply electric motors to drive the flue gas fan or air fan or other consumers, thus increasing the efficiency of using the energy introduced with the fuel in steam boiler.

\section{References}

1. D. Einstein, E. Worrell, M. Khrushch, Steam systems in industry: Energy use and energy efficiency improvement potentials (Lawrence Berkeley National Laboratory, 2001)

2. I.V. Ion, G. Ciocea, F. Popescu, Therm. Eng., S 1 (2016)

3. I. Binev, V. Rasheva, S. Tasheva, N. Georgieva, M. Konstantinov, ARTTE 3 (2015)

4. Z. Kolev, P. Mushakov, P. Zlatev P., Proceedings of Conference of University of Ruse 57, 1 (2018).

5. P.G. Negreanu, I. Oprea, Proceedings of COFRET'12 Symposium, Sozopol, Bulgaria (2012)

6. I. Iliev, A. Terziev, H. Beloev, E3S Web Conf. 180, (2020)

7. L. Qiang, Waste Heat Recovery from Fossil-Fired Power Plants by Organic Rankine Cycles, in Organic Rankine Cycles for Waste Heat Recovery - Analysis and Applications (S. Lasala, IntechOpen 2019)

8. S. Ogriseck, Appl. Therm. Eng. 29 14-15 (2009)

9. K.S. Omendra, Fuel 267 (2020)

10. K.S. Omendra, Renew. Energy 143 (2019)

11. W. Maolin et al., Appl. Therm. Eng. 86 (2015)

12. Y. Yuan, et al., Energy Procedia 61 (2014)

13. M.Qu, O. Abdelaziz, H. Yin, Energ Convers Manag. 87 (2014)

14. H.M.D.P. Herath, M.A. Wijewardane, R.A.C.P. Ranasinghe, J.G.A.S. Jayasekera, Energy Rep. 6 (2020)

15. S. Lecompte, A.O. Oyeniyi, M.N. Christos, L. Marija, K. Alihan, M. van den Broek, M. De Paepe, Energies 10 (2017)

16. Z.Q. Wang, N.J. Zhou, J. Guo, X.Y. Wang, Energy 40 (2012)

17. B.T. Liu, K.H. Chien, C.C. Wang, Energy 29(8) (2004)

18. L. Tocci, T. Pal, I. Pesmazoglou, B. Franchetti, Energies, 10413 (2017)

19. D. Wang, X. Ling, H. Peng, L. Liu, L.L. Tao, Energy 501 (2013)

20. T. Kankeyan, W. Anusha, J. Saliya, R. Chathura, Energy Procedia 156 (2019)

21. V.O. Guillermo, C.G. Javier, D.F. Jorge, Resources 9, 2; (2020)

22. B. Vanslambrouck, I. Vankeirsbilck, S. Gusev, M. De Paepe, 2nd European Conference on Polygeneration, Tarragona, Spain (2011)

23. S. Jian, L. Ping, T. Jaime, M.N. Christos, Front. Energy Res. 8:6. (2020)

24. R. Turton, R.C. Bailie, W.B. Whiting, J.A. Shaeiwitz, Analysis, Synthesis and Design of Chemical Processes (Pearson Education, London 2008).

25. S. Taehong, C.K. Kyung, Energy Procedia 129 (2017) 